\title{
Evaluation of General, Pathological, and Radiological Features of Male Breast Cancer
}

\author{
Fariba Zarei ${ }^{1}$, Fereshte Bagheri ${ }^{1,},{ }^{*}$ Amin Dehdashtian ${ }^{1}$ and Majid Akrami ${ }^{2}$ \\ ${ }^{1}$ Department of Radiology, Medical Imaging Research Center, Shiraz University of Medical Sciences, Shiraz, Iran \\ ${ }^{2}$ Department of Surgery, Shiraz University of Medical Sciences, Shiraz, Iran \\ "Corresponding author: Department of Radiology, Medical Imaging Research Center, Shiraz University of Medical Sciences, Shiraz, Iran. Tel: +98-9176046722, Email: \\ fereshteebagherii@gmail.com
}

Received 2019 December 11; Revised 2020 July 04; Accepted 2020 July 11.

\begin{abstract}
Background: Male breast cancer (MBC) is an infrequent disease and a scarcely researched topic. Since the incidence of male breast cancer is increasing and so far, management advices have been concluded from results of trials in female patients, there has been a growing interest in this field of research.

Objectives: In this study, we aimed to evaluate the general, radiological and pathological features of MBC patients.

Patients and Methods: We retrospectively reviewed the medical records of MBC patients who had been referred to breast clinic, Shahid Motahari in Shiraz, Iran, between 2005 and 2018. Data regarding general characteristics of patients such as demographic information, age, and also past history of any cancer, family history of breast cancer, mammogram and ultrasound findings, stage, size and location of tumor, histopathology of tumor, metastasis, treatment modalities and follow-up time were attained by reviewing medical records.

Results: Fifty-one patients with MBC were included with the mean age of 58.4 years. Invasive ductal carcinoma was the most prevalent pathologic type. By use of the Kaplan Meier survival estimate, survival probability of patients for each time interval after diagnosis was calculated. There was a decline over time until about 85 months after diagnosis when it reached a plateau state above $50 \%$. Age, human epidermal growth factor receptor 2 (HER2) and metastasis showed to lower the survival time by increasing the hazard ratio. Only 13 patients had mammography and 22 had an ultrasound, which are less than $50 \%$ of the total number of patients.

Conclusions: This study showed that there is still unfulfilled need to evaluate MBC in order to find the best management guidelines such as screening in high risk populations, diagnosis, treatment, and follow-up. Risk factor evaluation, survival time, and diagnostic radiologic modalities have not been well assessed in $\mathrm{MBC}$ so far.
\end{abstract}

Keywords: Male, Breast Cancer, Radiology, Pathology

\section{Background}

Male breast cancer $(\mathrm{MBC})$ is an uncommon disease responsible for less than $1 \%$ of all breast cancer diagnoses worldwide (1). Limited research has been focused on this area of knowledge. Due to scarcity of this disease, no randomized trials have been performed so far(2). Since the incidence of male breast cancer is increasing (3), there has been a growing interest in this field of research.

Most information on breast cancer in men has been obtained from retrospective studies with several decades duration. Proper treatment guidelines for MBC have not yet been noticeably established and management advices have been concluded from results of trials in female patients (4). However, it seems that most of these studies were not adjusted for sexual variance. For example, breast cancer develops at older ages among men compared to women (5). Moreover, lifestyle and cancer risk factors can differ between men and women. Additionally, breast cancer in men happens with higher stage, possibly due to delayed breast cancer detection $(6,7)$ and also is usually low grade and commonly hormone receptor-positive (8). Notable differences in the biological and clinicopathological features have been discussed between male and female breast cancer (9).

There is also a geographical discrepancy reported in MBC occurrence (10). In Iran, it has been reported that MBC is responsible for $0.65 \%$ of all cancer patients in men (11).

Comparable to breast cancer in women, $\mathrm{MBC}$ is predicted to be affected simultaneously by different risk fac- 
tors including clinical disorders relating to hormonal imbalances, certain occupational and environmental exposures, and genetic risk factors including breast cancer (BRCA) genes. Environmental factors, especially occupational carcinogen exposure, might as well add to MBC risk by interacting with genetic causes (12).

\section{Objectives}

In this study, we aim to retrospectively evaluate the general, radiologic and pathologic features, management, and prognosis of MBC patients referred to a breast clinic with the diagnosis of breast carcinoma between 2005 and 2018 to see if there is any specific pattern in this rare disease.

\section{Patients and Methods}

We retrospectively reviewed the medical records of MBC patients who had been referred to breast clinic, Shahid Motahari in Shiraz, Iran, between 2005 and 2018. Data regarding general characteristics of patients including demographic information, age, past history of any cancer, family history of breast cancer, mammogram and ultrasound findings, side, stage, size and location of tumor, histopathology of primary tumor, metastasis, treatment modalities (surgery, chemotherapy, radiation and hormone therapy) and follow-up time were attained by reviewing medical records.

The Kaplan-Meier estimate was applied to compute the survival probability in time intervals after diagnosis. Cox proportion hazard model was also used to test the effect of other variables such as age, stage, and receptor on survival time. P value less than 0.2 was considered as statistically significant. The acquired data are expressed as mean and percent. Statistical analyses were performed by SPSS software version 10.5 (Statistical Package for the Social Sciences, Chicago, Ill).

\section{Results}

Fifty patients with MBC were investigated in the current study with the mean age (at time of diagnosis) of 58.4 years (range, 37-83 years) of whom $2 \%$ were diagnosed before $40 \%$ and $42 \%$ after the age of sixty. Most of them were diagnosed between 40 and 60 years. Most of the patients (84\%) were living in the urban area, 63\% were low educated, and $93 \%$ of the patients were married. One of the cases had bilateral breast cancer, $17 \%$ had a positive family history of breast cancer, and 13\% had other malignancies. The majority of them had BMI in the normal range. Complete general features of the patients are presented in Table 1.

The most prevalent pathologic type was invasive ductal carcinoma (Figure 1) and then papillary carcinoma. One of the cases was myofibroblastoma. Estrogen was the most common existed receptor reported. Lymphatic invasion was seen to be the most frequent pathway of invasion. Metastasis was evaluated in the patients by chest $\mathrm{X}$ ray, computed tomography (CT) scan (taken from the brain, chest, and abdomen), bone scan, and in a few cases magnetic resonance imaging (MRI) (taken from the brain and spine). The histopathologic characteristics are listed in Table 2. Among them, the involvement of both breasts was almost similar.

Survival data for 40 patients (80\%) were available. There were nine deaths reported among the patients due to breast cancer and three due to other health conditions (diabetic mellitus, end stage renal disease, and renal cancer). Mean follow-up time, from diagnosis to the time of last visit, was 55.1 months.

Based on Kaplan Meier survival estimate, the survival probability of patients for each time interval after diagnosis was calculated which were on the decline over time until about 85 months after diagnosis, when it reached a plateau state above 50\% (Figure 2). As shown in Table 3, the hazard ratio of some of the variables was evaluated. Among them, age, human epidermal growth factor receptor 2 (HER2), and metastasis showed to lower the survival time by increasing the hazard ratio. The higher the hazard ratio, the higher the effect of the factor on survival. Furthermore, metastasis with hazard ratio of approximately 4.5 had the highest impact on survival.

Sonographic and mammographic findings are listed in Table 4. Only 13 of the patients had mammography and 22 of them had ultrasound, which were less than 50 $\%$ of the total patients. The mentioned numbers reveal the underestimation of these diagnostic tools in the process of decision making. On the other hand, the majority of existing radiologists' reports was incomplete with nonstandard terms.

\section{Discussion}

Breast cancer is a rare disease in men, responsible for about less than $1 \%$ of all breast cancer patients in the United States (13) and 0.1\% of cancer mortality in men (14).

Formerly, the incidence of male breast cancer was thought to be relatively steady, but now it is on an in- 


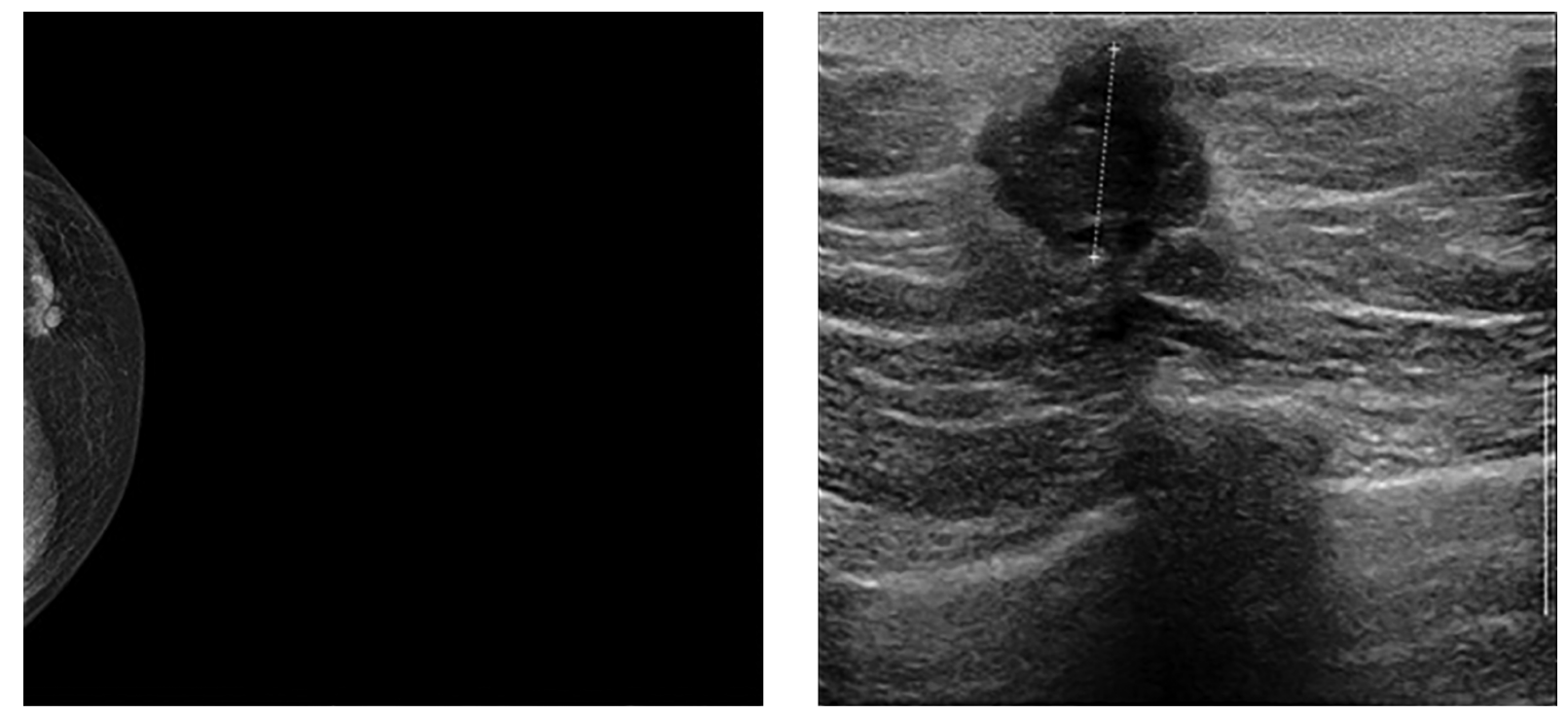

Figure 1. Mammogram and ultrasound of a $47 \mathrm{y} / 0$ male with palpable mass with pathology of invasive ductal carcinoma

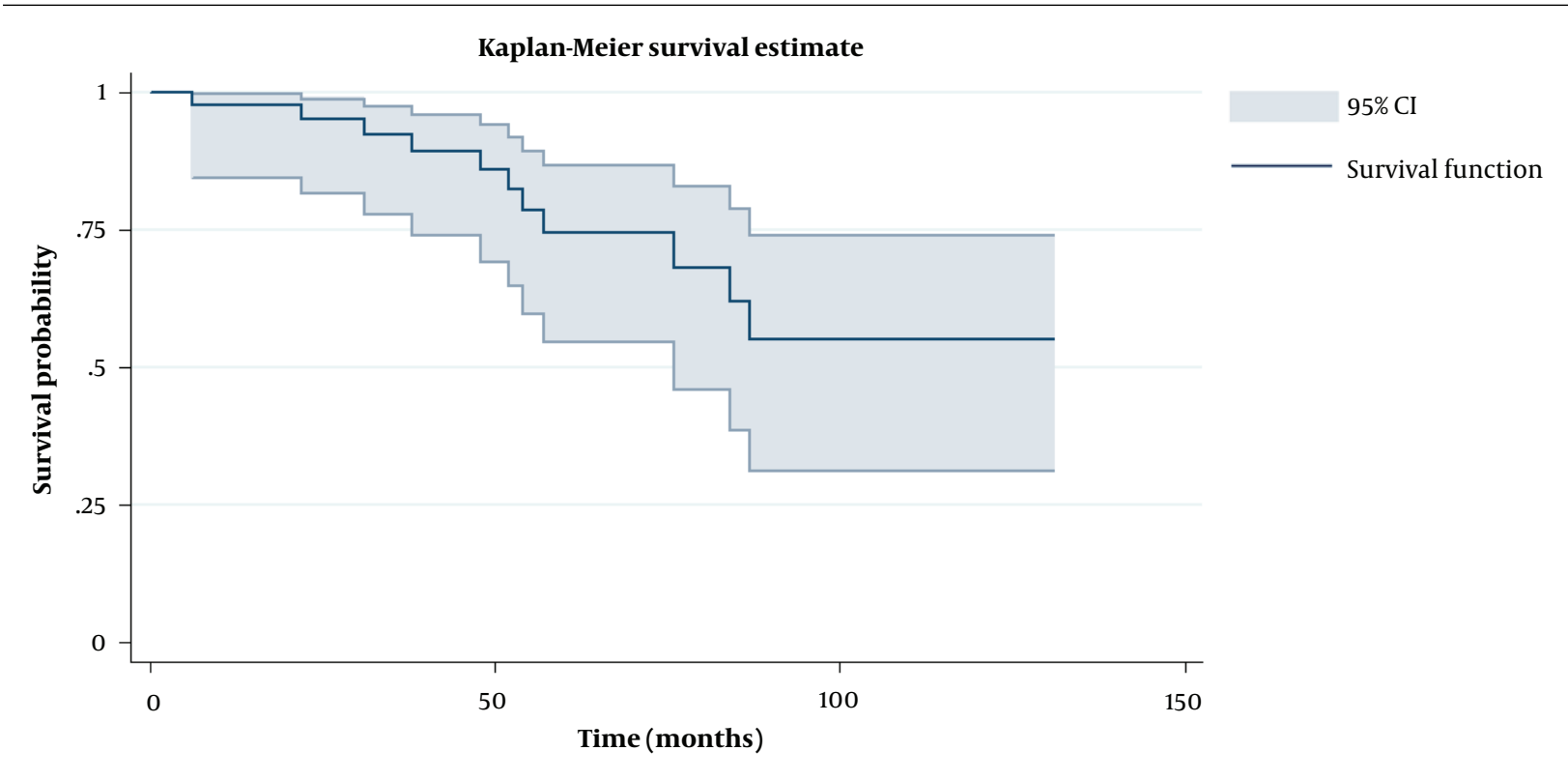

Figure 2. Kaplan-Meier survival estimate 


\begin{tabular}{|c|c|}
\hline General Characteristics of Patients & Number (\%) \\
\hline \multicolumn{2}{|l|}{ Age at diagnosis } \\
\hline$<40$ & $2(4)$ \\
\hline $40-60$ & $27(54)$ \\
\hline$>60$ & $21(42)$ \\
\hline \multicolumn{2}{|l|}{ Residence status } \\
\hline Urban & $26(84)$ \\
\hline Rural & $5(16)$ \\
\hline Missed data & 19 \\
\hline \multicolumn{2}{|l|}{ Education status } \\
\hline Illiterate & $2(7)$ \\
\hline Low-educated & $17(63)$ \\
\hline high-educated & $8(30)$ \\
\hline Missed data & 23 \\
\hline \multicolumn{2}{|l|}{ Marital status } \\
\hline Single & $2(7)$ \\
\hline Married & $27(93)$ \\
\hline Missed data & 21 \\
\hline \multicolumn{2}{|l|}{ BMI } \\
\hline$<18.5$ & $2(7)$ \\
\hline $18-24.9$ & $15(48)$ \\
\hline $25-29.9$ & $9(29)$ \\
\hline$>30$ & $5(16)$ \\
\hline Missed data & 19 \\
\hline \multicolumn{2}{|l|}{ Routine exercise } \\
\hline Yes & $16(55)$ \\
\hline No & $13(45)$ \\
\hline Missed data & 21 \\
\hline \multicolumn{2}{|l|}{ Past medical history } \\
\hline Diabetic mellitus & $6(25)$ \\
\hline Hyperlipidemia & $5(20)$ \\
\hline Hypertension & $4(16)$ \\
\hline Others & $9(39)$ \\
\hline Missed data & 26 \\
\hline \multicolumn{2}{|l|}{ Family history of breast cancer } \\
\hline Yes & $5(17)$ \\
\hline No & $24(83)$ \\
\hline Missed data & 31 \\
\hline \multicolumn{2}{|l|}{ Family history of other malignancies } \\
\hline Yes & $13(43)$ \\
\hline No & $17(57)$ \\
\hline Missed data & 20 \\
\hline \multicolumn{2}{|l|}{ Tobacco use } \\
\hline Yes & $8(26)$ \\
\hline No & $22(74)$ \\
\hline Missed data & 20 \\
\hline \multicolumn{2}{|l|}{ Alcohol use } \\
\hline Yes & 0 \\
\hline No & $27(100)$ \\
\hline Missed data & 23 \\
\hline
\end{tabular}

Abbreviation: BMI, body mass index

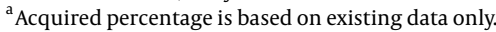

creasing trend (3). Incidence of MBC increased considerably from 0.86 to 1.06 per 100,000 population over the last few decades (4). The global difference of MBC is similar to breast cancer in women, with higher incidence in North America and Europe and lower incidence in Asia (15).

Despite extensive epidemiologic reports on female breast cancer, little is achieved about the etiology of $\mathrm{MBC}$ mostly due to scarcity of this disease in men. The low incidence of this disease also causes inadequate sample size to evaluate the relationship between risk factors and breast cancer. Tissue availability presents another challenge. Another issue in this field is the insufficient amount of tissue sample. Due to the small size of tumor in men, an insufficient amount of tissue is available for research purposes for molecular and genetic studies. Despite rarity of studies, several risk factors for MBC have been clarified.

Genetic factors seem to have an important role in MBC such as BRCA2 gene mutations found in the majority of inherited breast cancers in men. Furthermore, a positive family history of breast cancer and Klinefelter syndrome are constantly related to $\mathrm{MBC}$ (16). The most common observed epidemiologic risk factors include disorders accompanied with elevated estrogen levels, gynecomastia, occupational and environmental exposures, and dietary factors. Other examined risk factors for MBC are obesity, testicular disorders (including cryptorchidism, mumps orchitis, and orchiectomy), and radiation exposure (17).

In the present study, the majority of patients were middle aged men with low education and normal BMI in contrast to previous studies that showed obesity is one of the possible risk factors for MBC (18). Furthermore, the mean age of $\mathrm{MBC}$ in this series is lower than that of another population based study in Iran on MBC (19). Despite slight dominancy of left-sided involvement in other studies (20), both breasts were involved similarly in this study.

As mentioned before, metastasis was evaluated in the patients via chest X ray, CT scan (taken from the brain, chest and abdomen), bone scan and in a few cases, MRI (taken from the brain and spine). Involvements of other organs were mostly seen in the liver and lung in contrast to bone involvement in females, which is the most frequent site for distant metastases (21).

Similar to other investigations (22), family history of breast cancer and other malignancies was notable (17\% and $43 \%$, respectively) in our patients.

Fortunately, most of the patients felt the need to seek medical intervention in the early phase and were diagnosed with a tumor size of less than $2 \mathrm{~cm}$ (55\%) and in stage II (59\%) of the disease leading to a better prognosis. 


\begin{tabular}{|c|c|c|c|}
\hline Features & Number (\%) & Features & Number (\%) \\
\hline Size $(\mathbf{c m})$ & & Involvement side & \\
\hline$<2$ & $16(55)$ & Right & $23(46)$ \\
\hline $2-5$ & $9(31)$ & Left & $26(52)$ \\
\hline$>5$ & $4(14)$ & Bilateral & $1(2)$ \\
\hline Missed data & 21 & Metastasis to other organs & \\
\hline Histopathological type & & Liver & 4 \\
\hline Invasive ductal carcinoma & $38(90)$ & Lung & 3 \\
\hline Papillary carcinoma & $3(7)$ & Bone & 0 \\
\hline Others & $1(3)$ & Brain & 0 \\
\hline Missed data & 8 & Fine needle aspiration & \\
\hline Stage at diagnosis & & Positive & $17(80)$ \\
\hline I & $11(32)$ & Negative & $1(6)$ \\
\hline II & $20(59)$ & Suspicious & $3(14)$ \\
\hline III & $3(9)$ & Missed data or No FNA & 29 \\
\hline Missed data & 16 & Surgery type & \\
\hline In situ component & & Mastectomy & $44(95)$ \\
\hline Yes & $12(43)$ & Quadrantectomy & $2(5)$ \\
\hline No & $16(57)$ & Missed data & 4 \\
\hline Missed data & 22 & Sentinel lymph node biopsy & \\
\hline Invasion & & Yes & 4 \\
\hline Lymphatic & $10(34)$ & Not mentioned or not performed & 46 \\
\hline Vascular & $7(24)$ & Chemotherapy treatment (mean sessions: 6) & \\
\hline Perineural & $6(21)$ & Yes & $40(95)$ \\
\hline All & $6(21)$ & No & $2(5)$ \\
\hline Receptor & & Missed data & 8 \\
\hline Estrogen & $44 / 46(95)$ & Radiotherapy treatment (mean sessions: 20) & \\
\hline Progesterone & $41 / 46(89)$ & Yes & $24(67)$ \\
\hline \multirow[t]{2}{*}{ Her2 } & $24 / 34(70)$ & No & $12(33)$ \\
\hline & & Missed data & 14 \\
\hline \multicolumn{4}{|c|}{ Hormone therapy } \\
\hline & & Letrozole for 40 months & $8(16)$ \\
\hline & & Tamoxifen for 41.4 months & $29(58)$ \\
\hline & & Herceptin & $2(4)$ \\
\hline & & Survival in mean follow up time of 55.1 months & \\
\hline & & Expired by breast cancer & 9 \\
\hline & & Expired by other reasons & 3 \\
\hline
\end{tabular}

Abbreviations: FNA, fine needle aspiration; HER2, human epidermal growth factor receptor 2 


\begin{tabular}{|c|c|c|}
\hline Parameters & Hazard ratio & Pvalue \\
\hline Involvement side (right or left) & 1.53 & 0.49 \\
\hline Age & 1.05 & 0.07 \\
\hline Stage & 0.63 & 0.25 \\
\hline Progesterone receptor & 0.61 & 0.59 \\
\hline Estrogen receptor & 0.86 & 0.92 \\
\hline Her2 & 1.81 & 0.18 \\
\hline Metastasis & 4.55 & 0.01 \\
\hline
\end{tabular}

Abbreviations: HER2, human epidermal growth factor receptor 2

\begin{tabular}{|c|c|c|c|}
\hline Mammographic features $($ number of patients $=13$ ) & Number & Sonographic features (number of patients $=\mathbf{2 2}$ ) & Number \\
\hline Mass features & & Mass features & \\
\hline Number & 13 & Number & 20 \\
\hline Asymmetry & 0 & Non-mass & 1 \\
\hline Gynecomastia & 0 & Gynecomastia & 1 \\
\hline Number of mass & & Number of mass & \\
\hline Single & 11 & Single & 21 \\
\hline Multiple & 2 & Multiple & 1 \\
\hline Border & & Border & \\
\hline Circumscribed & 2 & Circumscribed & 2 \\
\hline Irregular & 4 & Irregular & 2 \\
\hline Lobulated & 1 & Lobulated & 3 \\
\hline Not mentioned & 6 & Not mentioned & 15 \\
\hline Density & & Echogenicity & \\
\hline Hyperdense & 7 & Hypoechogenicity & 19 \\
\hline Not mentioned & 6 & Not mentioned & 3 \\
\hline Location & & Location & \\
\hline Retroareolar & 7 & Retroareolar & 6 \\
\hline Upper outer quadrant & 3 & Axillary tail & 1 \\
\hline Not mentioned & 3 & Lower outer quadrant & 1 \\
\hline & & Not mentioned & 8 \\
\hline BIRADS & & BIRADS & \\
\hline IV or V & 7 & IV or V & 13 \\
\hline II & 2 & II & 2 \\
\hline Not mentioned & 4 & Not mentioned & 7 \\
\hline
\end{tabular}

Abbreviation: BIRADS, breast imaging reporting and database system

Radical mastectomy and adjuvant therapy such as chemoradiation and hormone therapy were the most popular treatment planning. As expected, adjuvant tamoxifen was the most administered hormone therapy among pa- tients regarding a high proportion of positive expression of estrogen and progesterone receptor (95\% and $89 \%$, respectively). Age, HER2, and metastasis were the most prognostic factors for survival among our patients; metastasis 
with the highest hazard ratio was placed first.

In contrast to female breast cancer, radiologic evaluation was neglected eventually as the diagnostic tool in decision making. Due to lack of proper experience and education in this field (due to scarcity of MBC), the capacity of these modalities has not been fulfilled yet. The mammographic and sonographic reports of patients in this study were incomplete and not straight forward. Unfortunately, the presented data was what we had in our health system and not what we gathered. We were aware of the suboptimal reporting and incomplete descriptions. Since this was a retrospective study, we could not revise it. In comparison to other fields such as pathology, the available data was considerably low. The proper application of ultrasound and mammogram could lead to better management and screening if needed and avoid unnecessary actions.

Nonetheless, among the available ultrasound and mammograms, only two of the malignant lesions were falsely reported as benign and BIRADS (breast imaging reporting and database system) II, of which one was marked as gynecomastia.

In conclusion, there is still need to evaluate MBC in order to find the best management guidelines such as screening in high-risk populations, diagnosis, treatment, and follow-up. Our study has the expected draw backs of descriptive epidemiologic studies especially for this rare disease, including retrospective registry assessment, missing data, and non-standardized definitions. Small sample size for risk assessment was also another limitation. Additional descriptive studies providing population based evidence are needed for further evaluation of the fruitful adjuvant therapies and associated risk factor for male breast cancer.

\section{Footnotes}

Authors' Contribution: F. Z, F. B, A.D and M.A developed the original idea and the protocol, abstracted and analyzed data, and wrote the manuscript.

Conflict of Interests: None of the authors had conflict of interests related to the material or acquired results in the manuscript.

Ethical Approval: Code: IR.sums.med.rec.1397.494.

Funding/Support: This study was from the thesis of radiology specialty degree (Project no. 97-01-01-18118) of Fereshte Bagheri and supported by Shiraz University of Medical Sciences, Shiraz, Iran.

Informed Consent: The study was retrospective and we just reviewed the documents. Patients' identity was not revealed in the study.

\section{References}

1. Jemal A, Siegel R, Ward E, Hao Y, Xu J, Thun MJ. Cancer statistics, 2009. CA CancerJClin.2009;59(4):225-49. doi:10.3322/caac.20006.[PubMed: 19474385].

2. Bagley CS, Wesley MN, Young RC, Lippman ME. Adjuvant chemotherapy in males with cancer of the breast. Am J Clin Oncol. 1987;10(1):5560. doi: 10.1097/00000421-198702000-00013. [PubMed: 3825994].

3. Tahmasebi S, Akrami M, Omidvari S, Salehi A, Talei A. Male breast cancer; analysis of 58 cases in Shiraz, South of Iran. Breast Dis. 2010;31(1):29-32. doi: 10.3233/BD-2009-0293. [PubMed: 20644250].

4. Giordano SH, Cohen DS, Buzdar AU, Perkins G, Hortobagyi GN. Breast carcinoma in men: a population-based study. Cancer. 2004;101(1):51-7. doi: 10.1002/cncr.20312. [PubMed: 15221988].

5. Anderson WF, Althuis MD, Brinton LA, Devesa SS. Is male breast cancer similar or different than female breast cancer? Breast Cancer Res Treat. 2004;83(1):77-86. doi:10.1023/B:BREA.0000010701.08825.2d. [PubMed: 14997057].

6. Fentiman IS, Fourquet A, Hortobagyi GN. Male breast cancer. The Lancet. 2006;367(9510):595-604. doi:10.1016/s0140-6736(06)68226-3.

7. Pant $K$, Dutta U. Understanding and management of male breast cancer: a critical review. Med Oncol. 2008;25(3):294-8. doi:10.1007/s12032007-9034-y. [PubMed: 18074245].

8. Giordano SH, Buzdar AU, Hortobagyi GN. Breast cancer in men. Ann Intern Med. 2002;137(8):678-87. doi: 10.7326/0003-4819-137-8-20021015000013. [PubMed: 12379069].

9. Perkins GH, Middleton LP. Breast cancer in men. BMJ. 2003;327(7409):239-40. doi: 10.1136/bmj.327.7409.239. [PubMed: 12896911]. [PubMed Central: PMC1126640].

10. Park S, Kim JH, Koo J, Park BW, Lee KS. Clinicopathological characteristics of male breast cancer. Yonsei Med J. 2008;49(6):978-86. doi: 10.3349/ymj.2008.49.6.978. [PubMed: 19108022]. [PubMed Central: PMC2628013].

11. Goya M. Iranian annual cancer registration report. Tehran, Iran: Ministry of Health and Medical Education, Health Deputy, Center for Disease Control and Prevention; 2007.

12. Palli D, Masala G, Mariani-Costantini R, Zanna I, Saieva C, Sera $\mathrm{F}$, et al. A gene-environment interaction between occupation and BRCA1/BRCA2 mutations in male breast cancer? Eur J Cancer. 2004;40(16):2474-9. doi: 10.1016/j.ejca.2004.07.012. [PubMed: 15519522].

13. Landis SH, Murray T, Bolden S, Wingo PA. Cancer statistics, 1999. CA Cancer J Clin. 1999;49(1):8-31. 1. doi: 10.3322/canjclin.49.1.8. [PubMed: 10200775].

14. W G. Male breast cancer. Diseases of the breast. 2nd ed. Philadelphia: Lippincott Williams \& Wilkins; 2000. p. 661-7.

15. Schottenfeld D, Lilienfeld AM, Diamond H. Some observations on the epidemiology of breast cancer among males. Am J Public Health Nations Health. 1963;53:890-7. doi: 10.2105/ajph.53.6.890. [PubMed: 13992391]. [PubMed Central: PMC1254174].

16. Ottini L, Masala G, D'Amico C, Mancini B, Saieva C, Aceto G, et al. BRCA1 and BRCA2 mutation status and tumor characteristics in male breast cancer: a population-based study in Italy. Cancer Res. 2003;63(2):3427. [PubMed: 12543786].

17. Sasco AJ, Lowenfels AB, Pasker-de Jong P. Review article: epidemiology of male breast cancer. A meta-analysis of published case-control studies and discussion of selected aetiological factors. Int J Cancer. 1993;53(4):538-49. doi: 10.1002/ijc.2910530403. [PubMed: 8436428]. 
18. Ewertz M, Holmberg L, Tretli S, Pedersen BV, Kristensen A. Risk factors for male breast cancer-a case-control study from Scandinavia. Acta Oncol. 2001;40(4):467-71. doi: 10.1080/028418601750288181. [PubMed: 11504305].

19. Salehi A, Zeraati H, Mohammad K, Mahmoudi M, Talei AR, Ghaderi A, et al. Survival of male breast cancer in fars, South of iran. Iran Red Crescent Med J. 2011;13(2):99-105. [PubMed: 22737442]. [PubMed Central: PMC3371920].

20. Scott-Conner CE, Jochimsen PR, Menck HR, Winchester DJ. An analysis of male and female breast cancer treatment and survival among de- mographically identical pairs of patients. Surgery.1999;126(4):775-80. discussion 780-1. [PubMed: 10520928].

21. Shaffrey ME, Mut M, Asher AL, Burri SH, Chahlavi A, Chang SM et al. Brain metastases. Curr Probl Surg. 2004;41(8):665-741. doi: 10.1067/j.cpsurg.2004.06.001. [PubMed: 15354117].

22. Friedman LS, Gayther SA, Kurosaki T, Gordon D, Noble B, Casey G, et al. Mutation analysis of BRCA1 and BRCA2 in a male breast cancer population. Am JHum Genet.1997;60(2):313-9. [PubMed: 9012404]. [PubMed Central: PMC1712407]. 